\title{
The structure of the Karay river basin by the longitudinal slopes of the river beds and the average gradients of water catchments slopes
}

\author{
Mikhail Bukovskiy ${ }^{1}$, Kirill Kuzmin ${ }^{1}$, Maria Chernova $^{1 *}$, and Elena Vishniakova ${ }^{2}$ \\ ${ }^{1}$ Tambov State University named after G.R. Derzhavin, 33 Internatsional'naya str., 392000, Tambov, \\ Russia \\ ${ }^{2}$ Saint Petersburg State University, 7/9 Universitetskaya nab., 199034, Saint-Petersburg, Russia
}

\begin{abstract}
The problems of water lag time during flood forecasting, the rate of pollution spreading over the basin area in the event of industrial accidents, the transport of suspended and dissolved substances by rivers, and planning of erosion control measures are very relevant today. Within the framework of the basin approach, an elementary water catchment can be adopted as an elementary unit for the analysis of a particular territory. At the same time, river bed slopes determine the power of the water flow, and the average slopes of water catchments significantly affect the formation of river flow, the nature of the hydrological regime and determine the erosion potential of the territory. The object of the study is the basin of the Karay river, located in the southeastern part of the OkaDon plain. The Karay river is a right tributary of the Khoper river (the Don river basin). For the Karay river basin the river bed slopes and average gradients of catchment slopes are calculated and analyzed. The calculations were based on the digital elevation model created in GIS MapInfo. It is shown that the average slopes of the territories within the Karay river basin range from $0.4^{\circ}$ to $1.4^{\circ}$.
\end{abstract}

\section{Introduction}

Relief is one of the main factors in the formation of surface runoff and erosionaccumulative processes. Relief determines the differentiation of the landscapes even within the local territory [1]. A basin can be called a geofunctional territorial unit of land. The maximum runoff, the depth of groundwater, the intensity of snowmelt, the peculiarities of the water regime of the territory, the type of soil, and, therefore, the formation of various ecological communities largely depend on the nature of the relief of basin area.

A wide range of theoretical and applied issues of modern science can be developed using geographic information systems (GIS). In hydrology, GIS have become a multifunctional research tool that provides the ability to calculate the numerous morphometric parameters of river catchments, model dangerous hydrological phenomena [2], identify active erosion processes [3], and solve other problems.

${ }^{*}$ Corresponding author: chernovamarusya@,mail.ru 
The urgent task is to calculate the lag time on the slopes when forecasting floods, water inflow to ponds and reservoirs, and developing operating modes of collector structures [4, 5]. The problem of water travel with a storm drain is also considered by I.K. Skribny [6].

Foreign authors, in particular, Frasson et al. [7], using river axial lines elaborated with the help of Landsat images and a digital elevation model, created spatially continuous maps of average annual river width, slope, mean sinuosity, and catchment area for rivers wider than $90 \mathrm{~m}$. During the analysis of the distribution of these properties, their typical ranges were determined and the correlation between the river form and slope were investigated.

Seo and Breidenbach believe that in the forecast of river flow in the long run it is advisable, in addition to precipitation, to take into account estimates of soil moisture and slopes of water catchments [8]. Zhao et al. [9] analyzed the model for the development of the velocity and length of sediment flows taking into account the geometry of sloping surfaces, physical and mechanical parameters of the sliding sediment, and the change in mass due to possible processes of erosion or deposition. The results of the study are important for identifying potentially vulnerable areas in terms of the development of erosion processes.

The slope of the river bottom determines the main driving force of the flow. The greater the slope of the bottom, the greater the speed of the flow and, accordingly, its depth is less [10].

The slopes of the catchment area and the longitudinal slopes of the river beds, formed by the erosion-accumulative process, largely determine the peculiarities of the formation of river flow, the nature of the hydrological regime, as well as the rate of spread of pollutants in emergency situations in manufacturing and in agriculture.

According to the guidelines for the organization of arable land in conditions of water erosion of soils [11], taking into account the steepness of the slopes is one of the first stages of land planning for crops, which emphasizes the importance of studying slopes in the context of studying the structure of the basin.

The main objective of this work is to analyze the longitudinal slopes of river beds and the gradients of catchments slopes in the Karay river basin.

\section{Data and methods}

The object of study is the basin of the Karay river (in the upper reaches of the Mokry Karay). This is the middle river in the southeast of the Oka-Don plain, in the west of the Saratov region of Russia. It flows from north to south, partly along the border between the Saratov and Tambov regions. The source is located near the village of Dmitrievka of the Turkovsky district, it enters the Khoper river from the right bank near the village of Bolshoy Karay, Romanovsky district, Saratov region. The studied river system is affected by significant anthropogenic transformation. Water dividing spaces and water resources are intensively used in agricultural production.

The work is based on original data. Measurements of lengths, areas and elevation differences were carried out using GIS MapInfo. To do this, based on Shuttle Radar Topography Mission (SRTM) images, a digital elevation model (DEM) of the Karay river basin was built. SRTM data accurately conveys the relief of open spaces, but they have the disadvantage that radar imagery recognizes forests, building roofs and other obstacles that are not «real» surfaces. Therefore, for the most reliable calculation of morphometric parameters, the DEM of the Karay river basin was also constructed on the basis of topographic maps, by means of vectoring contour lines. Then a comparative analysis and generalization of the data of the two models was performed.

The longitudinal profile of each of the rivers was constructed according to the elevations of the source and mouth of the river, as well as the elevations of the mouths of 
each inflowing tributary. Then, the total fall of the studied rivers was calculated, the average slope was calculated, and the type of longitudinal profile was determined. The profiles based on scale are made in the graphics editor CorelDRAW.

When calculating the longitudinal slopes of the river beds and the average slopes of catchments, we adhered to the methodological recommendations of the State Hydrological Institute [12] and the most common classification of longitudinal profiles based on the distribution of slopes along the length of the river, given, in particular, in the works of A.I. Chebotaryov [13].

\section{Results and discussion}

At the first stage of the study we constructed 11 longitudinal profiles of the largest river systems of the Karay river basin. The profiles were built for all watercourses with a length of more than $15 \mathrm{~km}$.

Fig. 1 shows the longitudinal profile of the Karay river bed.

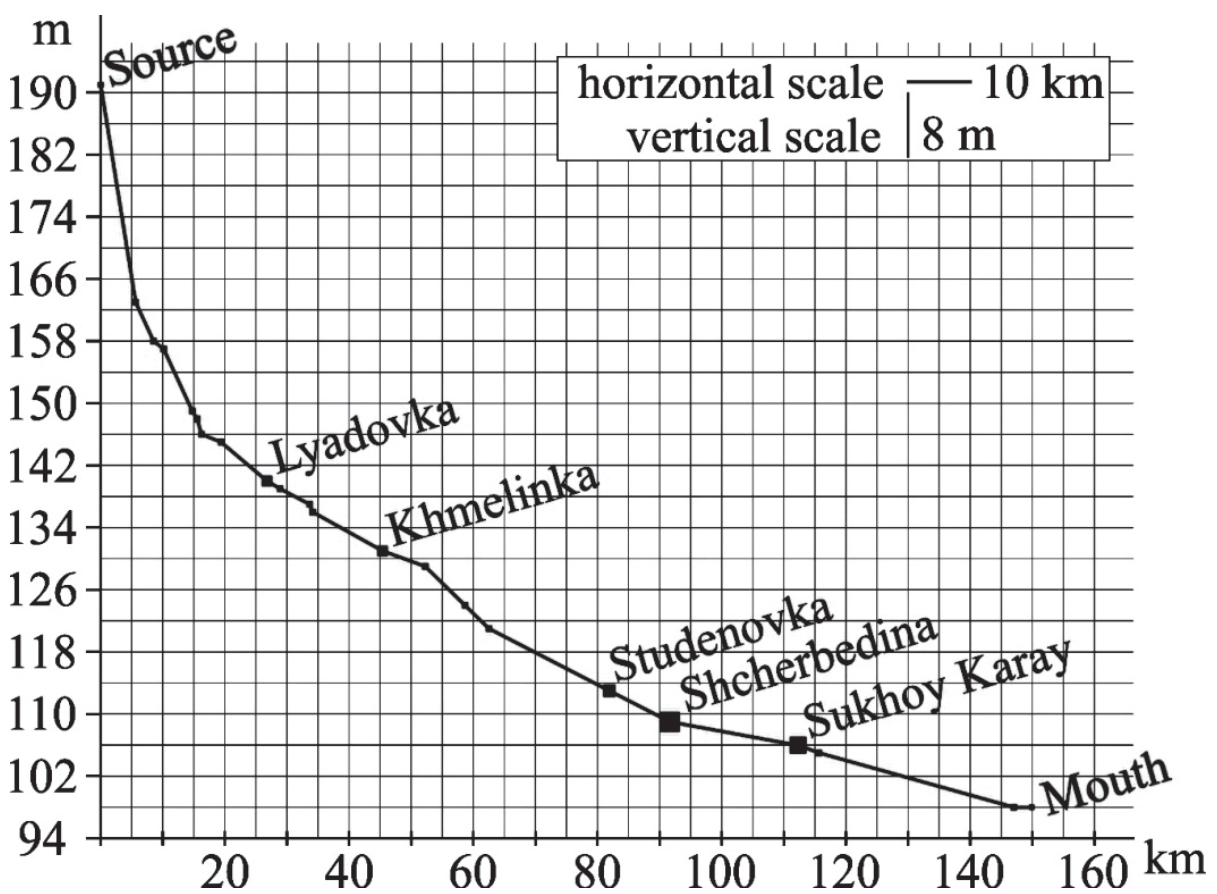

Fig. 1. The longitudinal profile of the Karay river bed.

Concave, rectilinear shapes of profiles, as well as slightly concave, which can be considered intermediate, were clearly traced in the studied rivers. A smooth concave longitudinal profile is typical of lowland rivers, where steep slopes are characteristic of the source of the river, and the most gentle - for the lower reaches. A rectilinear profile is usually observed in small rivers and is characterized by relatively uniform slopes throughout the river bed.

The results of the analysis of longitudinal profiles are shown in Table 1.

However, the river slope is an average value, giving a poor idea of the relief and erosion-accumulative processes in the river basin. The selected watercourses have different lengths of the river bed, and for a detailed assessment of their longitudinal slopes, we divided each studied profile into sections $5 \mathrm{~km}$ long, taking the sources of watercourses as reference points. The slopes of all sections were calculated separately. Near the mouth there 
was always a residue not equal to $5 \mathrm{~km}$. If it was less than $2.5 \mathrm{~km}$, then it was reckoned to the last section, if more, it was considered as a separate section. The river bed network with an aggregate length of $456 \mathrm{~km}$ was divided into 90 five-kilometer sections, grouped into 5 categories of slope values. The result is shown in Fig. 2.

Table 1. The results of the calculation of the average river slope and profile analysis.

\begin{tabular}{|l|c|c|c|c|}
\hline \multicolumn{1}{|c|}{ River name } & $\begin{array}{c}\text { Total fall of the } \\
\text { river }(\mathrm{m})\end{array}$ & $\begin{array}{c}\text { River slope } \\
(\%)\end{array}$ & $\begin{array}{c}\text { River slope } \\
(\mathrm{sm} / \mathrm{km})\end{array}$ & Profile form \\
\hline Karay & 93 & 0.621 & 62.1 & concave \\
\hline Khmelinka & 47 & 2.67 & 267 & slightly concave \\
\hline Studenovka & 67 & 2.124 & 212.4 & slightly concave \\
\hline Volzhanchik & 55 & 2.077 & 207.7 & rectilinear \\
\hline Shcherbedina & 84 & 1.115 & 111.5 & concave \\
\hline Shepelevka & 40 & 2.415 & 241.5 & rectilinear \\
\hline Kanava & 53 & 3.131 & 313.1 & rectilinear \\
\hline Krutoy & 49 & 2.918 & 291.8 & rectilinear \\
\hline Gryaznukha & 54 & 1.766 & 176.6 & slightly concave \\
\hline Tavolzhanka & 36 & 1.66 & 166 & slightly concave \\
\hline Sukhoy Karay & 64 & 1.216 & 121.6 & concave \\
\hline
\end{tabular}

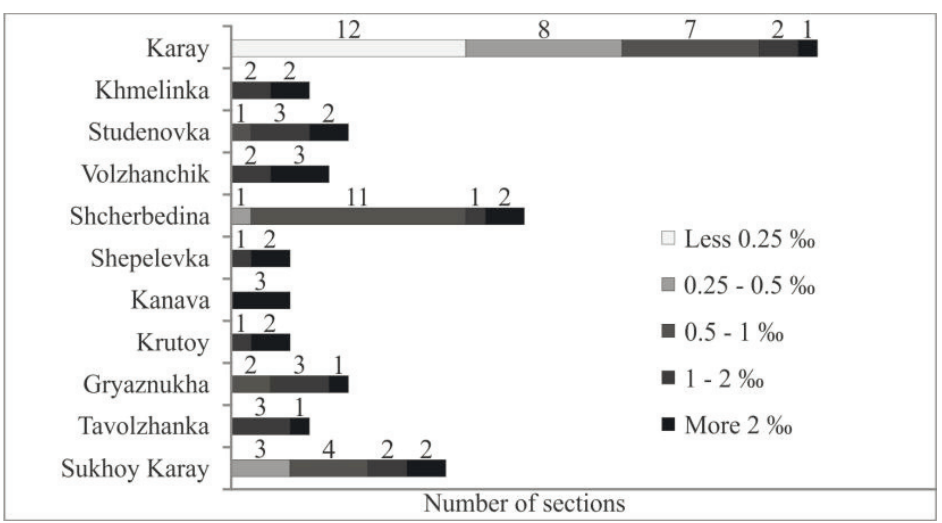

Fig. 2. The distribution of five-kilometer sections of rivers in the magnitude of the longitudinal slope.

The morphometric parameters of the upper links of the hydrographic network throughout the basin are very similar. On average, the slopes of more than $2 \%$ have the upper 10-kilometer sections of the river network, the slopes of 1-2\% are the sections of rivers following them. The sites in the category $0.5-1 \%$ prevail over the remaining categories, accounting for $28 \%$, but are present in a smaller part of the watercourses. The areas with a slope of $0.25-0.5 \%$ were recorded at three main watercourses. The slopes of less than $0.25 \%$ can only be observed in the lower reaches of the Karay river, the main trunk of the river network.

The second stage of the study was the calculation of the slopes of the basins. The calculations were carried out in the MapInfo software environment based on the DEM of the Karay river basin that we created. The results of morphometric calculations are presented in Table 2. The DEM is shown in Fig. 3.

The most gentle slopes $\left(0.4-0.5^{\circ}\right)$ are possessed by the Lyadovka, Malaya Gryaznukha, Tavolzhansky rivers. The average gradient of slopes increases to $1-1.4^{\circ}$ at watercourses with a larger catchment area and a large order in the hydrographic network. It correlates with the difference in altitude in the main basins: 96 meters near Mokry Karay and 
Shcherbedina, 92 meters near Studenovka, 78 meters near Volzhanchik, 74 meters near Sukhoy Karay.

Table 2. The results of the calculation of morphometric characteristics in the Karay river basin.

\begin{tabular}{|l|c|c|c|}
\hline \multicolumn{1}{|c|}{ Watercourse name } & Catchment area $\left(\mathrm{km}^{2}\right)$ & $\begin{array}{c}\text { Average gradient } \\
\text { of water catchment } \\
\text { slopes (\%) }\end{array}$ & $\begin{array}{c}\text { Average gradient } \\
\text { of water catchment } \\
\text { slopes (degree, }{ }^{\circ} \text { ) }\end{array}$ \\
\hline Karay & 2699.58 & 18.93 & 1.1 \\
\hline Mokry Karay & 842.37 & 20.36 & 1.2 \\
\hline Lyadovka & 60.11 & 8.36 & 0.5 \\
\hline Khmelinka & 75.01 & 14.45 & 0.8 \\
\hline Studenovka & 258.06 & 23.89 & 1.4 \\
\hline Volzhanchik & 112.65 & 24.2 & 1.4 \\
\hline Shcherbedina & 920.86 & 18.37 & 1.1 \\
\hline Shepelevka & 107.67 & 16.54 & 0.9 \\
\hline Kanava & 118 & 21.65 & 1.2 \\
\hline Krutoy & 51.86 & 19.56 & 1.1 \\
\hline Gryaznukha & 197.15 & 11.48 & 0.7 \\
\hline Malaya Gryaznukha & 63.48 & 7.35 & 0.4 \\
\hline Bolshaya Gryaznukha & 104.63 & 12.21 & 0.7 \\
\hline Tavolzhanka & 173.75 & 12.73 & 0.7 \\
\hline Tavolzhansky & 61.27 & 9.31 & 0.5 \\
\hline Sukhoy Karay & 389.87 & 20.57 & 1.2 \\
\hline Osinovka & 76.35 & 16.59 & 1 \\
\hline Berezovyy & 73.17 & 15.57 & 0.9 \\
\hline
\end{tabular}

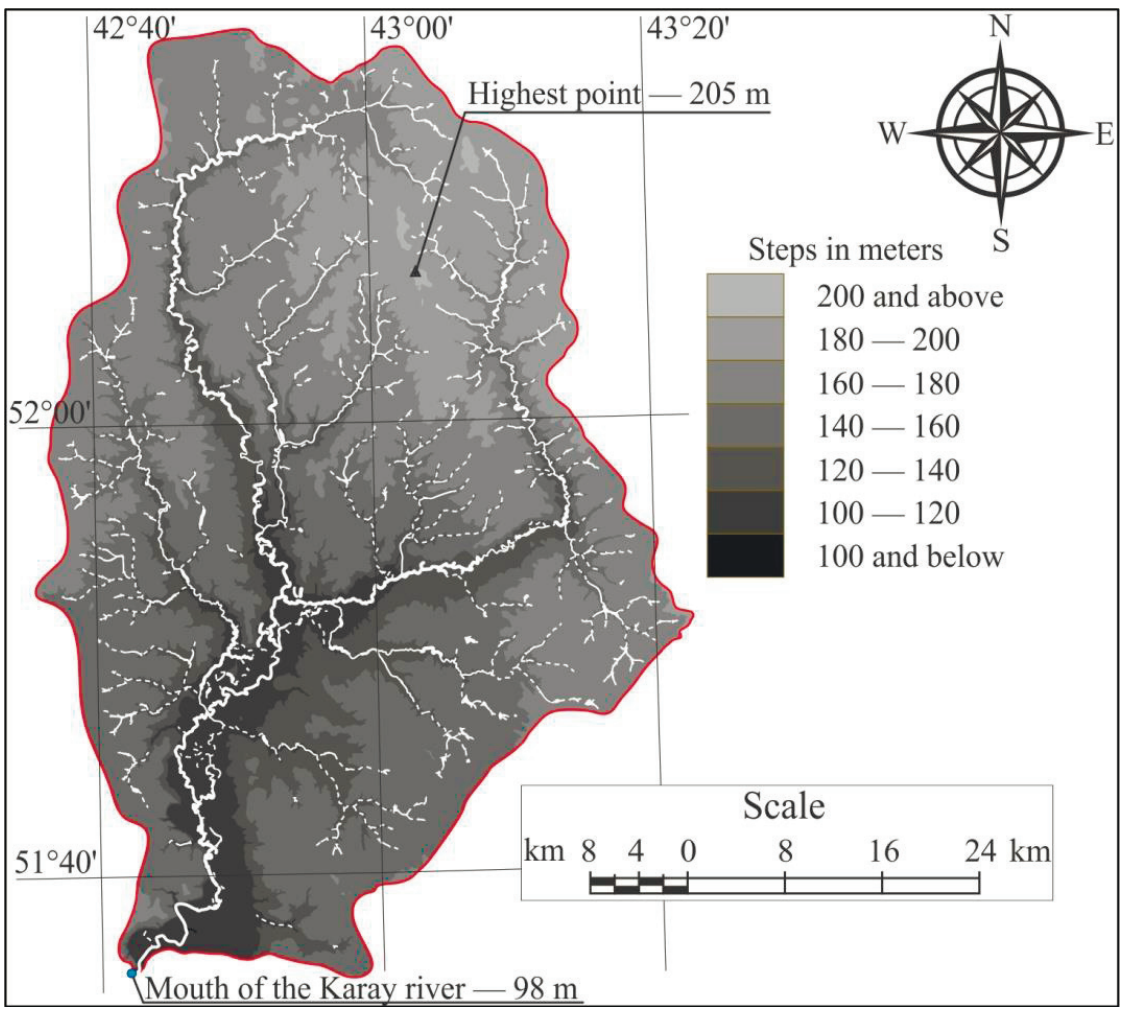

Fig. 3. Altitude map of the Karay river basin. 


\section{Conclusion}

Based on the results of the research, the following conclusions can be formulated.

The forms of the longitudinal profiles of the studied watercourses, and therefore their slopes, are typical of small and medium rivers of the Oka-Don plain. The Karay, being a medium river, has the most concave, developed profile. The remaining river bed systems have either slightly concave or rectilinear profile shape.

The average slope of the river beds ranges from 62 to $313 \mathrm{~cm} / \mathrm{km}$. The average gradient of water catchments slopes in the study area is from 735 to $2420 \mathrm{~cm} / \mathrm{km}$ or from $0.4^{\circ}$ to $1.4^{\circ}$.

\section{References}

1. K.A. Maltsev, A.G. Sharifullin, J. Geomorph. RAS, 3, 76-87 (2017)

2. U.P. Arzhanyh, V.V. Dolzhenkova, A.V. Zvyagintseva, Heliogeophysical Research., 9 (9), 89-98 (2014)

3. M.U. Zaitseva, I.I. Rysin, J. Bull. of UdmSU, 1, 87-9 (2017)

4. S.V. Budnik, J. Sci. notes of TauNU, 20 (59), 316-21 (2007)

5. S.V. Budnik, Culture of the peoples of the Black Sea, 151, 94-101 (2009)

6. I.K. Skribniy, J. Rus. Meteorol. and Hydrol., 12, 76-82 (1979)

7. Frasson, R.P.d.M., T.M. Pavelsky, M.A. Fonstad, M.T. Durand, G.H. Allen, G. Schumann, C. Lion, R.E. Beighley and X. Yang, J. Geophys. Res Lett., 46 (6) (2019)

8. D.-J. Seo and J. Breidenbach, J. Hydrometeorol., 3, 93-111 (2012

9. H.B. Zhao, Z.L. Ru, and C.X. Zhu ASCE in Int. Jour. of Geomech., 17 (2015)

10. M.V. Shmakova, J. Proc. of the RSHU, 40, 28-37 (2015)

11. V.V. Toptygin, Organization of arable land in conditions of water erosion of soils: method. instructions, p 94 (2018)

12. G 52.08.874-2018 «Determining the hydrographic characteristics by the map's method», 172 (2018)

13. A.I. Chebotaryov, General hydrology (land water) (Leningrad: Gidrometeoizdat Press, 1975), 530 